\title{
Treatment of vitreous floaters with neodymium YAG laser
}

Wu-Fu Tsai, Yen-Chih Chen, Chorng-Yi Su

\begin{abstract}
Fifteen cases of vitreous floaters with serious psychological reactions have been collected. By using a direct ophthalmoscope, causal vitreous opacities were detected. The opacities were photodisrupted with neodymium YAG laser, using energy levels of 5 to $7.1 \mathrm{~mJ}$ and total energy 71 to $742.0 \mathrm{~mJ}$. Symptoms completely disappeared immediately after treatment in all 15 cases. There were no intraoperative or postoperative complications noted during a follow up period of at least 1 year. To our knowledge, the use of neodymium YAG laser to treat vitreous floaters has not been previously described. Our initial experience indicates that the treatment is simple, safe, and effective.
\end{abstract}

(Br f Ophthalmol 1993; 77: 485-488)

The perception of floaters is a common complaint of ophthalmic patients, and may be symptomatic of serious vitreoretinal disorders: it may also occur commonly in otherwise normal eyes. In the latter situation floaters result from localised vitreous opacities that are products of either vitreous degenerations or posterior vitreous detachments. Although most of them will resolve spontaneously, some become coarse. Their natural history cannot be predicted. They are harmless and need no treatment. However, there are rare patients who may react so excessively to vitrous floaters that they are psychologically incapacitated. For these patients, it is worth employing more aggressive treatment to relieve their annoyance. We found that this type of floater usually results from localised vitreous opacities which could easily be photodisrupted to make the floaters disappear. Our report describes treatment using a neodymium YAG (NdYAG) laser for 15 patients with excellent results.

Department of Ophthalmology, Father Fox Memorial Hospital, Tainan, Taiwan, Republic of China W F Tsai Y C Chen C Y Su

Department of Ophthalmology, College of Medicine, National Taiwan University, Taipei, Taiwan, Republic of China

W F Tsai

Correspondence to: Dr Wu-Fu Tsai, Father Fox Memorial Hospital, 901 Chung Hua Road, Yung Kang Hsiang, Tainan, Taiwan Accepted for publication 25 March 1993

\section{Patients and methods}

Between July 1990 and June 1991, 15 patients with vitreous floaters were selected who met the following criteria for laser treatment: the floaters were caused by localised vitreous opacities; symptoms persisted for at least 3 months without evidence of regression; patients suffered fear, depression, or anxiety and strong desire for a fast cure; in some cases floaters obstructed the visual axis and occasionally interfered with vision. None of the patients had a history of retinal detachment, diabetic retinopathy, or other retinal diseases. If the vitreous floaters appeared in both eyes (cases 5,6,10,11, and 14) the more severely affected one was selected. Of these 15 patients, six were men and nine were women. Their ages ranged from 42 to 70 with an average age of 56.93 years.
Each patient had a thorough preoperative ophthalmic examination including visual acuity, tonometry, and a complete external eye examination. Vitreous study was performed by slit-lamp biomicroscopy with Goldmann's three mirror contact lens. Ocular fundus was examined thoroughly with indirect ophthalmoscopy and a 360 degree scleral depression to rule out a retinal break or detachment.

When taking individual patient histories, we emphasised the duration, number, shape, size, direction of motion, and movability of the vitreous floaters. In fact, we encouraged the patients to draw, if possible, exactly what they had seen.

As far as laser treatment was concerned, all of the above mentioned examinations were for documentation only. However, an ocular fundus examination with direct ophthalmoscopy was mandatory. Through the maximally dilated pupil, the ophthalmoscopy was initially focused on the disc, the lens wheel was moved from a lower black number toward a higher black number, and the patient was asked to move his eye from left to right. The opacity was seen to float by. Usually, they were centrally located and were less than three in number. The number of opacities was equal to that of the floaters; a single opacity always induced a single floater. If the number of opacities was larger than the number of floaters, the more centrally located opacities were the ones responsible for the floaters. The causal relationship between vitreous opacities and floaters was easily determined in this way. The exact locations, sizes, and shapes of the causal opacities were sketched in a three dimensional graph with the optic disc serving as a reference point. When the treatment was being performed, this graph might serve to show the exact location of the target opacity and, more importantly, to show the distance of the opacity from the retina so as to avoid damaging it. The actual distance of vitreous opacity from retina could be measured by focal difference between the opacity and retina as measured by direct ophthalmoscopy, or by ultrasonogram measurement.

\section{TREATMENT}

Informed consent was obtained in all cases. Thirty minutes before the treatment $1 \%$ mydriacyl was applied into the eye once or several times to obtain maximal pupillary dilatation. The instrument used was LASAG microruptor III, which is a $Q$ switch YAG laser. The instrument was properly aligned in such a fashion that the aiming beam and illumination beam crossed each other at a $15^{\circ}$ angle. The power was set at 5 or $7 \cdot 1 \mathrm{~mJ}$, occasionally $10 \mathrm{~mJ}$ per burst. (There were only these three settings 


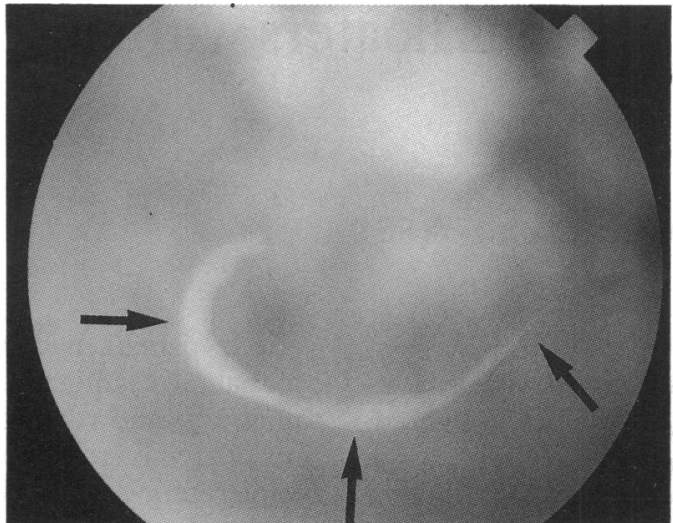

Figure $1 A$ Preoperative fundus photograph of the eye of case 4 with a free floating prepapillary opacity (arrows). The underlying retina appears blurry because focusing was on the vitreous opacity. There are medullated nerve fibres surrounding the optic disc (shown on the top of the photograph).

exceeding $4 \mathrm{~mJ}$ in the instrument which was manufactured in 1990). One pulse per burst was used for all patients who required only a single treatment session each. The contact lens used was a flat fundus lens. Either a fundus laser lens or a Goldmann's three mirror lens would be suitable. The image of the aiming beam was first focused on the retina and then moved slowly backwards to focus on the opacity. If the opacity was too small to be precisely focused on, then the aiming beam was focused on a spot which included the opacity and its immediate vicinity.

\section{Results}

Whether there was posterior jitreous detachment or not, where laser treatment was concerned the localised opacities of the 15 cases could be categorised into two groups: prepapillary and centrovitreal opacities. ${ }^{1}$ The prepapillary opacities were single membranous ring-shaped opacities (Weiss's ring) ${ }^{2}$ with shape and size corresponding to the contour of the optic disc (Fig 1A and Fig 2A). The centrovitreal opacities we defined were faint, discrete, fibrous opacities, floating freely near the centre of the vitreous cavity (Fig 3A and Fig 4A). The number of these opacities varied from one to three (Table 1 ).

The required laser energy varied with the size of the opacity in each case, ranging from 71.0 to $742.0 \mathrm{~mJ}$, with an average of $286.49 \mathrm{~mJ}$. If the

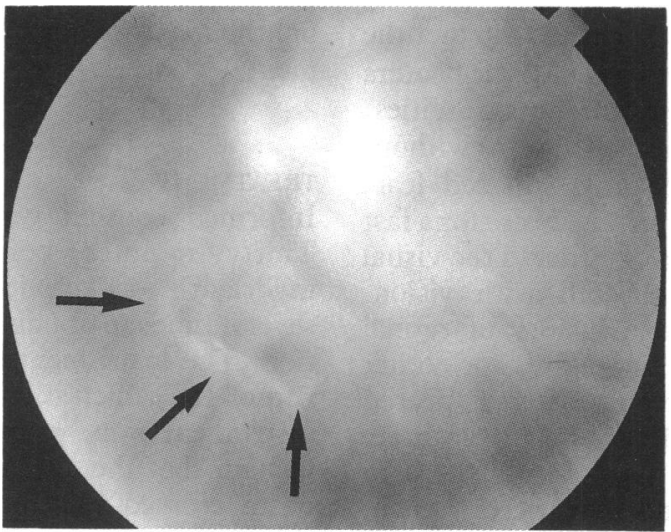

Figure 2A Preoperative fundus photograph of the eye of case 8 showing a prepapillary opacity (arrows).

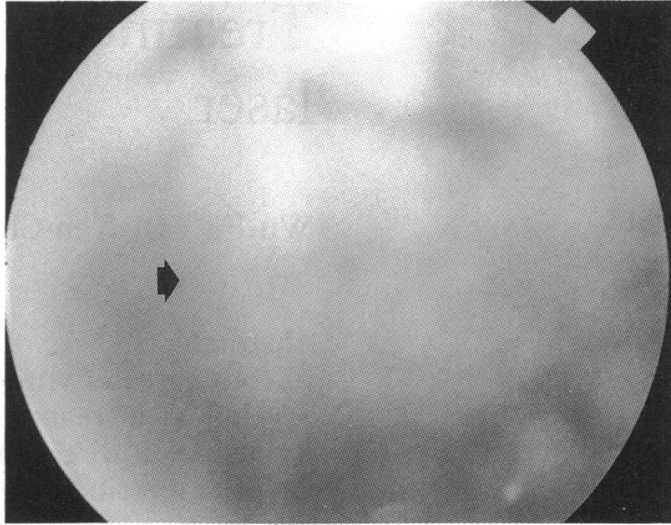

Figure $1 B$ Postoperative appearance. Note that the ringshaped opacity has been completely disrupted (arrow). The patient's symptom has completely disappeared.

laser burst was effective, the optical breakdown with fragmentation could be seen. In the first few cases of our study, approximately one half of the bursts produced sparks. Gradually, as we became more experienced, the effectiveness improved to nearly $100 \%$. The entire course of a treatment session for each patient usually took 20 minutes; this again became shorter as our technique improved. When the opacity was hit it bounded away and soon returned to the original site. At the same time, it gradually fragmented, became amorphous, and promptly disappeared (Figs 1B, 2B, 3B, and 4B). It took longer to completely disrupt the bigger prepapillary opacities.

In the initial five cases, the intraocular pressure was checked daily for 3 days and a fluorescein angiography was taken on the third day. There were no significant changes detected, therefore we discontinued these tests and only followed up the patients with regular examinations.

There were five patients with complaints of seeing floaters in both eyes. For these five patients, only one eye was treated; the fellow eye was left untreated. We found that the floaters and opacities disappeared in all of the five treated e. es but persisted and remained unchanged in the untreated eyes. These patients no longer had anxiety, possibly because of assurance obtained from the positive results in the treated eyes.

All patients were satisfied with the treatment and stated that their floaters disappeared

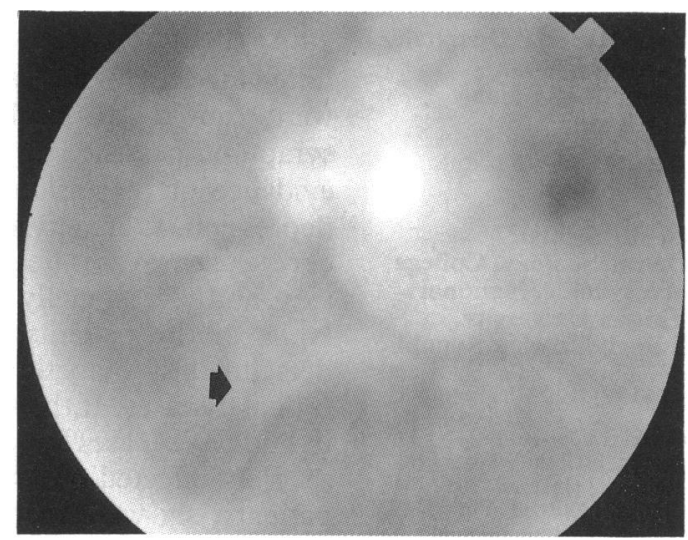

Figure 2B Postoperative appearance. Note that the opacity has been completely disrupted (arrow). 


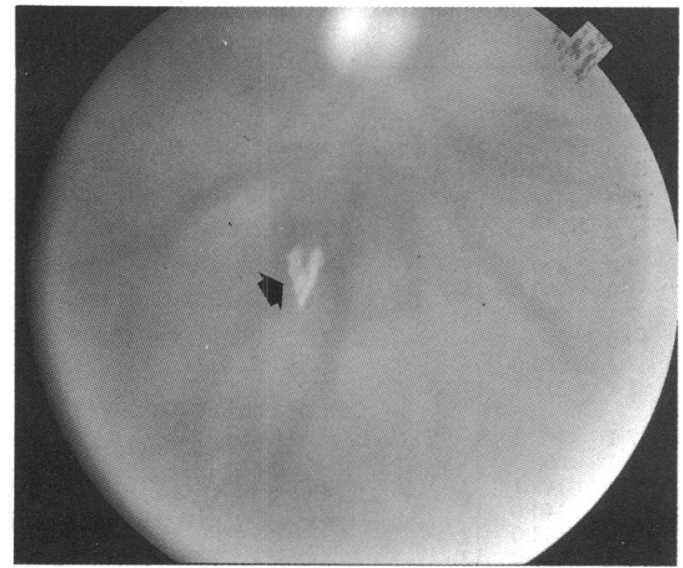

Figure 3A Preoperative fundus photograph of the eye of case 10 with a fibrous centrovitreal opacity (arrow).

immediately after the operation; their anxiety was dramatically relieved, too. During the 12 month follow up period, no patient showed any significant visual deterioration or recurrence of subjective floaters.

\section{Discussion}

In 1983, Murakami and associates ${ }^{1}$ reported the vitreous changes in 148 eyes with sudden onset of floaters. They had observed that $76 \%$ of the patients saw one or a few floaters and $24 \%$ saw many. The floaters were located primarily in the central field of vision. Eighty six per cent of the 136 patients were 50 years of age or older. There were two kinds of vitreous opacities that were responsible for floaters: prepapillary vitreous opacities and vitreous opacities in the posterior vitreous cavity near the macula. Our clinical observation is generally in agreement with Murakami's findings in all aspects mentioned above. In our present study, the number of opacities was usually one for prepapillary opacities and one to a few in centrovitreal opacities. The patients were usually 50 years or older. As far as treatment is concerned, most of the younger patients who complained of many floaters were usually untreatable because no opacity could be found using an ophthalmoscope. On the other hand, older patients who complained of many floaters were usually not suitable candidates for laser treatment because the opacities had usually resulted from retinal pathology,

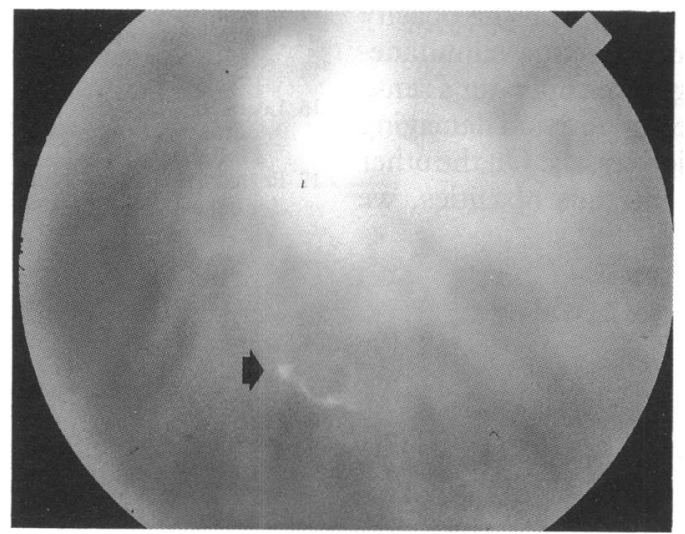

Figure 4A Preoperative fundus photograph of the eye of case 12 with a centrovitreal opacity (arrow).

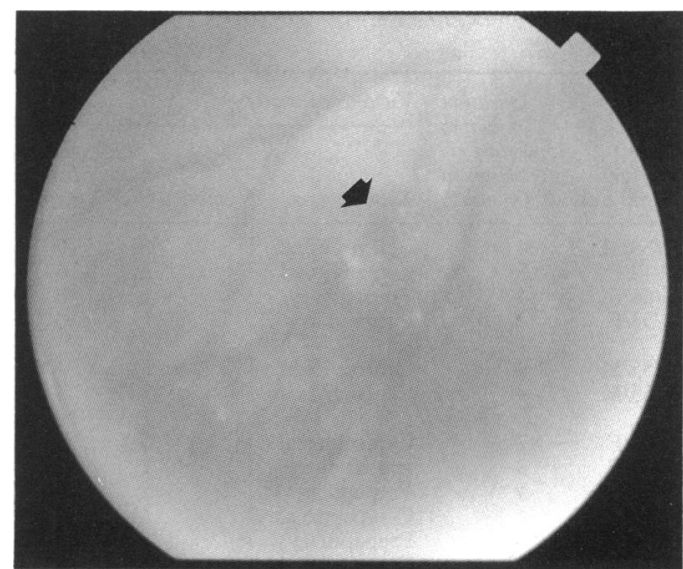

Figure 3B Postoperative appearance. The opacity has been disrupted, only traces could be seen with a direct ophthalmoscope (arrow). The patient's symptom has completely subsided.

which needed other specific treatment. Based on our experience, we estimate that about $90 \%$ or more of all vitreous floaters are technically treatable, regardless of their indications.

Application of Nd-YAG laser in the posterior segment is not popular as in the anterior segment. ${ }^{34}$ Most of the reports were on vitreolysis for vitreoretinal tractions in proliferative diabetic retinopathy ${ }^{678}$ or sickle cell retinopathy. 9 Other applications of laser for the treatment of vitreous cysts, ${ }^{10}$ cystoid macular oedema, ${ }^{11}$ or rhegmatogenous retinal detachment ${ }^{12}$ have been rarely reported. To our knowledge, use of Nd-YAG laser for treatment of vitreous floaters has not been previously described. The obstacle to more common application of the Nd-YAG laser in vitreous pathology is that it is known to potentially cause damage to the chorioretina. The complications include choroidal haemorrhage ${ }^{613}$ damage to the retinal pigment epithelium, ${ }^{14}$ transient retinal haemorrhage, ${ }^{5}$ and bleeding from perfused vascular bands.

However, some studies indicated that the threshold of the retinal damage caused by NdYAG laser is related to the potency of power used and the distance of focus from the retina. ${ }^{15}$ Because of the high power of laser energy, the focus should be kept to a minimum of $4 \mathrm{~mm}$ away from the retina. ${ }^{15}$ Although this result was obtained from an animal experiment, it still could be applied to clinical treatment. ${ }^{14}$ Fortu-

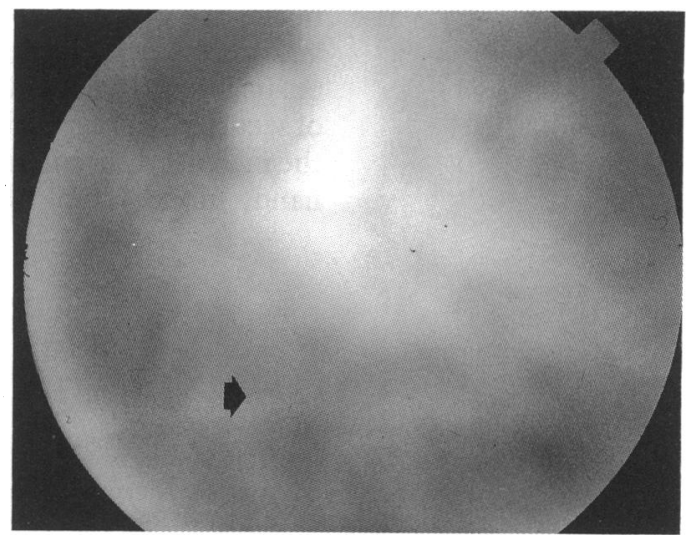

Figure $4 B$ Postoperative appearance. The opacity has been completely disrupted (arrow). 
Table 1 Summary of 15 patients who underwent neodymium YAG laser treatment for vitreous floaters

\begin{tabular}{|c|c|c|c|c|c|c|c|c|}
\hline \multirow{3}{*}{$\begin{array}{l}\text { Patient } \\
\text { No/Age } \\
\text { (years)/Sex }\end{array}$} & \multirow{3}{*}{$\begin{array}{l}\text { Duration } \\
\text { of floaters } \\
\text { before } \\
\text { treatment } \\
\text { (months) }\end{array}$} & \multicolumn{4}{|c|}{ Vitreous opacities } & \multirow{2}{*}{\multicolumn{2}{|c|}{ Laser doses }} & \multirow{3}{*}{$\begin{array}{l}\text { Duration of } \\
\text { follow up } \\
\text { (months) }\end{array}$} \\
\hline & & \multirow[b]{2}{*}{ Type } & \multirow[b]{2}{*}{ Number } & \multirow[b]{2}{*}{ Size } & \multirow{2}{*}{$\begin{array}{l}\text { Distance } \\
\text { from the } \\
\text { retina }(\mathrm{mm})\end{array}$} & & & \\
\hline & & & & & & $\begin{array}{l}\text { Burst } \\
(\boldsymbol{m} \mathcal{f})\end{array}$ & $\begin{array}{l}\text { Total } \\
(\boldsymbol{m} \mathcal{f})\end{array}$ & \\
\hline $1 / 63 / M$ & 4 & Centrovitreal & 1 & $\mathbf{M}$ & 10 & $7 \cdot 1$ & $340 \cdot 8$ & 18 \\
\hline $2 / 42 / F$ & 5 & Centrovitreal & 3 & M & $6-7$ & $5 \cdot 0$ & $400 \cdot 0$ & 18 \\
\hline $3 / 66 / F$ & 4 & Prepapillary & 1 & L & 6 & $5 \cdot 0$ & $600 \cdot 0$ & 18 \\
\hline $4 / 53 / \mathrm{F}$ & 2 & Prepapillary & 1 & $\mathbf{L}$ & 6 & $\begin{array}{r}7 \cdot 1 \\
10 \cdot 0\end{array}$ & $742 \cdot 0$ & 18 \\
\hline 5/55/M & 3 & Centrovitreal & 1 & $\mathbf{M}$ & 4 & $7 \cdot 1$ & $284 \cdot 0$ & 14 \\
\hline 6/55/M & 3 & Centrovitreal & 3 & $2 S$ & $5-7$ & $7 \cdot 1$ & $217 \cdot 1$ & 14 \\
\hline $7 / 51 / F$ & 7 & Centrovitreal & 1 & $S$ & 9 & $7 \cdot 1$ & $149 \cdot 1$ & 13 \\
\hline $8 / 54 / F$ & 3 & Prepapillary & 1 & L & 4 & $7 \cdot 1$ & $660 \cdot 3$ & 13 \\
\hline $9 / 62 / M$ & 4 & Prepapillary & i & $\bar{S}$ & 6 & $7 \cdot i$ & $149 \cdot 1$ & 13 \\
\hline $10 / 55 / \mathrm{F}$ & 4 & Centrovitreal & 1 & $\mathbf{M}$ & 5 & $5 \cdot 0$ & 140.0 & 13 \\
\hline $11 / 70 / M$ & 6 & Prepapillary & 1 & $S$ & 6 & $7 \cdot 1$ & $142 \cdot 0$ & 12 \\
\hline $12 / 52 / \mathrm{F}$ & 4 & Centrovitreal & 1 & s & 5 & $5 \cdot 0$ & 140.0 & 12 \\
\hline $13 / 57 / F$ & 4 & Prepapillary & i & L & 7 & $5 \cdot 0$ & 120.0 & 12 \\
\hline $14 / 58 / \mathrm{F}$ & 5 & Centrovitreal & 2 & $\bar{S}$ & $5-6$ & $7 \cdot 1$ & $71 \cdot 0$ & 12 \\
\hline $15 / 61 / F$ & 4 & Centrovitreal & 2 & M & $6-7$ & $7 \cdot 1$ & $142 \cdot 0$ & 12 \\
\hline
\end{tabular}

$\mathrm{S}=$ small; $\mathrm{M}=$ medium; $\mathrm{L}=$ large. Size of opacity is defined as small when its diameter is smaller than $1 / 2$ disc diameter, medium: $1 / 2$ to 1 disc diameter and large when it is larger than 1 disc diameter. In fibre-like opacities, the size is small when its length is smaller than 1 disc diameter and medium when larger than it. compared the direct ophthalmoscope with the indirect ophthalmoscope and preferred the former, simply because it has a higher magnification and so opacities can be localised more easily.

Theoretically, potential complications such as chorioretinal damage and lens damage might be expected, yet we never experienced any complications in our series. Fluorescein angiography performed after treatment disclosed no damage to the retina, either. We believe that precise focusing is the most important factor in avoiding complications.

It was reported that vitreous floaters are highly related to the posterior vitreous detachment (PVD). ${ }^{1}$ In our series, there were only two cases (case 2 and case 5) with no PVD before treatment, while in the other 13 cases, complete PVD was detected preoperatively. At the end of the follow up period, the two eyes with no PVD remained unchanged. However, in case 5, the untreated fellow eye developed complete PVD within 1 year. It is obvious that laser treatment would not influence the course of PVD.

Although we confined the indications for nately, almost all of the opacities that caused floaters in otherwise normal eyes happened to be located beyond this distance; this could be confirmed by ultrasonogram measurement. Moreover, the avascular nature and high mobility of opacities are additional advantages for laser treatment. Owing to their high mobility, it is easy to segregate the opacities from the underlying macula, optic disc, and major vessels simply by changing the position of the eyeball. In addition, the shield effect of the opacities may also reduce the amount of laser energy that reaches the retina. ${ }^{14}$ is All of these factors make photodisruption of vitreous opacities less risky than expected.

The importance of contact lens in vitreolysis cannot be overemphasised. ${ }^{16} 17$ Both effect and safety should be considered in its use. We realise that the contact lenses that are specially designed, such as Peyman's 25, 18, and $12.5 \mathrm{~mm}$, are useful for vitreolysis. ${ }^{317}$ However, they are not suitable for disruption of localised vitreous opacities because their magnification is so high that too many of the details of the vitreous body make the target opacity difficult to identify. Therefore, we recommend using the flat fundus lens of the Goldmann three mirror contact lens even though we realise its divergent effect on laser energy is less than that of Peyman's. The focal depth of a flat fundus lens is greater, which makes the operator able to focus on the opacity and observe the background retina simultaneously. This will not only give the operator a sense of security but also enable him to avoid damaging the macula, disc, and major vessels. On the other hand, in examining the vitreous opacities, we treatment to very strict criteria, by accumulating samples and experience, Nd-YAG laser may prove to be a safe and ideal method for treatment of all persistent vitreous floaters in the future.

1 Murakami K, Jalkh AE, Avila MP, Trempe CL, Schepens CL. Vitreous floaters. Ophthalmology 1983; 90: 1271-6.

2 Duke-Elder S. Diseases of the vitreous body. In: System of ophthalmology. St Louis: Mosby, 1976: Vol XI; 322, 341.

3 Steinert RF, Puliafito CA. The Nd-YAG laser in ophthalmology: principle and clinical application of photodisruption. Philadelphia: Saunders, 1985: 134-7.

4 Keates RD. Q-switched nanosecond pulsed Nd YAG laser. In: Aron-Rosa DN, ed. Pulsed YAG laser surgery. New Jersey: Slack, 1983: 51-5.

5 Aron-Rosa D, Greenspan DA. Neodymium:YAG laser vitreolysis. Int Ophthalmol Clin 1985; 25: 125-34.

6 Fankhauser F, Kwasniewski SF, van der Zypen E. Vitreolysis with the Q-switched laser. Arch Ophthalmol 1985; 103 1166-71.

7 Brown GC, Benson WE. Treatment of diabetic traction retinal detachment with the pulsed neodymium-YAG laser. $A m \mathcal{F}$ Ophthalmol 1985; 99: 258-62.

8 Brown GC, Scimeca G, Shields JA. Effects of the pulsed neodymium:YAG laser on the posterior segment. Ophthalmic Surg 1986; 17: 470-2.

9 Hrisomalos NF, Jampol LM, Moriarty BJ, Serjeant G, Acheson R, Goldberg MF. Neodymium-YAG laser vitreolysis in sickle cell retinopathy. Arch Ophthalmol 1987; vitreolysis in 105 : $1087-91$.

10 Ruby AJ, Jampol LM. Nd:YAG treatment of a posterior vitreous cyst. Am $\mathcal{F}$ Ophthalmol 1990;110: 428-9.

11 Katzen LE, Flieschman JA, Trokel S. YAG laser treatment of cystoid macular edema. Am f Ophthalmol 1983; 95: 589-92.

12 Fleck BW, Dhillon BJ, Khanna V, McConnell JM, Chawla HB. Nd:YAG laser augmented pneumatic retinopexy. Ophthalmic Surg 1988; 19: 855-8.

13 Puliafito KA, Wasson PJ, Steinert RF. Neodymium-YAG laser surgery on experimental vitreous membrane. Arch Ophthalmol 1984; 102: 843-7.

14 Jampol LM, Goldberg MF, Jednock N. Retinal damage from a Q-switched YAG laser. Am $\mathcal{f}$ Ophthalmol 1983; 96: 326-9.

15 Bonner RF, Meyers SM, Gaasterland DE. Threshold for retinal damage associated with the use of high-power retinal damage associated with the use of high-power
neodymium-YAG lasers in the vitreous. $A m \mathcal{F}$ Ophthalmol 1983; 96: 153-9.

16 Loertscher H, Fankhauser F. YAG laser contact lens theory (advanced). In: March WF, ed. Ophthalmic laser: current clinical uses. Thorofare, NJ: Slack, 1984: 69-83.

17 Peyman GA. Contact lenses for Nd:YAG application in the vitreous. Retina 1984; 4: 129-3i. 